
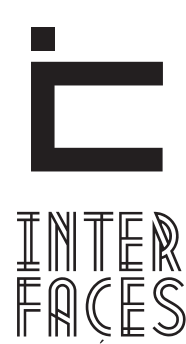

CIENTÍFICAS

HUMANAS E SOCIAIS

ISSN IMPRESSO 2316-3348

E-ISSN 2316-3801

DOI - 10.17564/2316-3801.2017v6n1p91-100

\title{
O CONCEITO DE PERVERSÃO NA SCIENTIA SEXUALIS E NA PSYCHOPATHIA SEXUALIS DE KRAFFT-EBING
}

\author{
THE CONCEPT OF PERVERSION IN SCIENTIA SEXUALIS AND IN KRAFFT-EBING'S PSYCHOPATHIA SEXUALIS \\ EL CONCEPTO DE PERVERSIÓN EN LA SCIENTIA SEXUALIS Y EN LA PSYCOPHATIA SEXUALIS DE KRAFFT-EBING
}

Lucas Carvalho Peto ${ }^{1}$

\section{RESUMO}

Objetiva-se elucidar o conceito de perversão no cerne da scientia sexualis do século XIX e na psychothia sexualis de Krafft-Ebing. Este trabalho possui caráter conceitual. No caso específico deste artigo, o desenvolvimento do objeto se da mediante a articulação de dois gêneros de atividades: análise e síntese. 0 primeiro se refere à análise de material bibliográfico. Esta análise é realizada mediante seleção de textos, parágrafos e trechos de textos específicos que são tomados como "unidades de análise". O material primordial são os escritos de Foucault, um texto de Deleuze (2009) e uma obra de Krafft-Ebing (2001). 0 segundo gênero de atividade é relativo à organização interpretativa, ou reconstrução, do material analisado. A partir dessa estrutura metodológica, parte-se de breve contextualização acerca da configuração político-econômica europeia nos séculos XVIII e XIX para demonstrar o contexto em que ocorre a emergência do predominío do discurso médico sobre a questão das perversões. Posteriormente, são apresentadas análises sobre a configuração epistemológica do discurso médico no século XIX e apresenta-se como resultado a forma como essa configuração fundamenta a scientia sexualis. Por fim, são analisados os postulados de Krafft-Ebing acerca da perversão. Conclui-se que na scientia sexualis do século XIX e na obra de Krafft-Ebing a perversão aparece como um conjunto de práticas de caráter estritamente biológico.

\section{PALAVRAS-CHAVE}

Epistemologia da Psicologia. História das Idéias Psicológicas. Sexualidade. 


\section{ABSTRACT}

The aim is to elucidate the concept of perversion at the heart of nineteenth-century scientia sexualis and Krafft-Ebing psychothia sexualis. This work has a conceptual character. In the specific case of this article, the development of the object occurs through the articulation of two genera of activities: analysis and synthesis. The first refers to the analysis of bibliographic material. This analysis is performed by selecting texts, paragraphs and excerpts from specific texts that are taken as "units of analysis". The primordial material is the writings of Foucault, a text by Deleuze (2009) and a work by Krafft-Ebing (2001). The second type of activity is related to the interpretative organization, or reconstruction, of the analyzed material. From this methodological structure, a brief contextualization about the European political-economic configuration in the eighteenth and ninete-

\section{RESUMEN}

Se pretende elucidar el concepto de perversión en el corazón de la scientia sexualis del siglo XIX y en la psychothia sexualis de Krafft-Ebing. Este trabajo tiene carácter conceptual. En el caso específico de este artículo, el desarrollo del objeto se da mediante la articulación de dos géneros de actividades: análisis y síntesis. El primero se refiere al análisis de material bibliográfico. Este análisis se realiza mediante la selección de textos, párrafos y fragmentos de textos específicos que se toman como "unidades de análisis". El material primordial son los escritos de Foucault, un texto de Deleuze (2009) y una obra de Krafft-Ebing (2001). El segundo género de actividad es relativo a la organización interpretativa, o reconstrucción, del material analizado. A partir de esa estructura metodológica, se parte de breve contextualización acerca de la configuración político-económica europea en los siglos XVIII y XIX para enth centuries is taken to demonstrate the context in which the emergence of the predominance of medical discourse on the question of perversions takes place. Subsequently, analyzes are presented on the epistemological configuration of medical discourse in the nineteenth century and the result is the way in which this configuration is based on scientia sexualis. Finally, the postulates of Krafft-Ebing on perversion are analyzed. It is concluded that in nineteenth-century scientia sexualis and in the work of Krafft-Ebing perversion appears as a set of strictly biological practices.

\section{KEYWORDS}

Epistemology of Psychology. History of Psychological Ideas. Sexuality.

demostrar el contexto en que ocurre la emergencia del predominio del discurso médico sobre la cuestión de las perversiones. Posteriormente, se presentan análisis sobre la configuración epistemológica del discurso médico en el siglo XIX y se presenta como resultado la forma como esa configuración fundamenta la scientia sexualis. Por último, se analizan los postulados de Krafft-Ebing acerca de la perversión. Se concluye que en la scientia sexualis del siglo XIX y en la obra de Krafft-Ebing la perversión aparece como un conjunto de prácticas de carácter estrictamente biológico.

\section{PALABRAS CLAVE}

Epistemología de la Psicología. Historia de las Ideas Psicológicas. Sexualidad. 


\section{INTRODUÇ̃̃̃O}

Neste artigo, objetiva-se elucidar o conceito de perversão no cerne da scientia sexualis do século XIX e na psychothia sexualis de Krafft-Ebing. Para tanto, parte-se de breve contextualização acerca da configuração político-econômica europeia nos séculos XVIII e XIX.

A partir do século XVIII, intensificando-se no século XIX, houvera um esforço para engendrar uma visão do corpo, e das práticas sexuais, compatível com a ordem social. Esta compatibilidade se coadunava com o respeito à religião e o contínuo aumento demográfico. Além disso, era impulsionada pela crescente demanda por mão de obra. As incitações econômicas e políticas demandavam utilidade às práticas sexuais. Práticas regulares, e reguladas, administradas pelo poder público em prol do "bem-estar" da população. Estas práticas configuravam-se como ponto nevrálgico das questões políticas e econômicas (FOUCAULT, 1998, p. 2008).

Neste contexto, o corpo emergira como agente de práticas sexuais transgressivas, configurando-se como lugar primevo de "crimes" contra a religião, a moral e a sociedade. 0 corpo apareceu como algoz das impotentes "[...] restrições sociais que visam conter as práticas sexuais dentro dos limites estabelecidos pelas convenções e pelas leis" (GRIECO, 2009, p. 217).

A partir do início do século XIX o eixo se deslocara do aumento populacional para a disciplinarização dos sujeitos. 0 discurso desenvolvido a partir do século XIX intentava menos uma defesa da sociedade do que um combate às "anormalidades". Para Foucault $(2001,2002)$, partindo-se do problema jurídico da responsabilidade se desvelara a molecularidade da periculosidade. É a partir dessa configuração que o discurso médico-positivo, o discurso científico, adquirira primazia sobre as práticas sexuais.

\section{A BASE EPISTEMOLÓGICA DO DISCURSO MÉDI- CO DO SÉCULO XIX}

No século XIX, o discurso médico estava em plena evolução epistemológica (GIAMI, 2005). 0 discurso médico sobre as práticas sexuais e, de forma mais específica, sobre a perversão, também oscilava. Esta oscilação se definia pela alternância entre a primazia do somático, do anátomo-fisiológico, e a primazia do sistema nervoso. Giami (2005) mapeia dois "estilos" de raciocínio dominantes. 0 estilo de raciocínio anatômico, que diria respeito principalmente à medicalização da masturbação como conduta e como etiologia de toda uma série de perturbações somáticas. $\mathrm{E}$ o estilo de raciocínio psiquiátrico, que rompe com a abordagem anatômica da sexualidade e que contribui para a emergência da sexualidade moderna.

$\mathrm{Na}$ gênese desta configuração discursiva da medicina do século XIX jaz a influência dos postulados de Comte e Claude Bernard (CANGUILHEM, 2000). Ambos influenciaram as conceitualizações acerca dos fenômenos "normais" e "patólogicos" nos discursos médicos e filosóficos do século XIX. Os postulados comtianos difundiram-se largamente na literatura médica e psicológica. A extensão da profusa influência de Bernard sobre a medicina, e a filosofia, do século XIX não é menor.

Nos escritos de Comte, o patológico instaura leis para o normal. As variações do estado patológico ordenam o estado normal, porquanto o estado patológico figura "[...] como substituto de uma experimentação biológica muitas vezes impraticável - sobretudo no homem" (CANGUILHEM, 2000, p. 23). Com efeito, afirma-se a identidade entre normal e patológico para determinar-se o primeiro. Renan apoia-se nas teses comtianas para assegurar a primazia dos estados desviantes sobre os "ordinários". Corroborando os escritos de Comte, Renan afirma, que "[...] a psicologia da humanidade deverá ser edificada sobretudo a partir do estudo das loucuras da humanidade, de seus sonhos, de suas alucinações" (CANGUILHEM, 2000, p. 24).

As concepções comtianas influenciaram também a metodologia de Ribot. Para estes, o estado patológi- 
co é uma experimentação sutil que atinge o inacessível. Logo, ao debruçarem-se sobre o estudo do patológico, os médicos, cientistas, psicólogos, e literatos, disporiam de um meio poderoso, fecundo em resultados, para postular sobre o normal.

O inverso caracteriza o pensamento de Claude Bernard; visando-se racionalizar o patológico, os estudos de Bernard dirigem-se do normal para o patológico. Da terapêutica em rompimento com o empirismo, a fisiologia emerge como dispositivo para desnudar o patológico. Sobre essa fisiologia-anatomia-morfologia pura debruçam-se os médicos. Reverberando as ideias de Bernard, o discurso médico do século XIX reitera a indissociável conexão entre fisiologia e patologia. Ela subjaz e inscreve-se no corpo, sustenta suas condutas, é o princípio ativo destas condutas. Neste cenário, apresentam-se os perversos, perversos sexuais, como espécie.

\section{A SCIENTIA SEXUALISDO SÉCULO XIX}

A partir do século XIX, o discurso científico-positivo, com seu exponente maior nos postulados médicos, ascendera sobre as práticas sexuais. Porém, ao longo do século XIX, dois registros diversos, inerentes a esse discurso, circunscreveram tais práticas. Uma biologia reprodutiva amparada em uma normatividade científica geral, e uma medicina do sexo, uma scientia sexualis (FOUCAULT, 1988). A última, caudatária de fontes extrínsecas ao discurso científico, se pautara na cientificidade da primeira como caução para encobrir demandas morais, econômicas, políticas, sociais e culturais.

Os postulados da scientia sexualis sobre as práticas sexuais, operaram, concomitantemente, com caráter epistêmico duplo. Como fragmento da episteme positiva, científica, e como episteme da doxa, calcada nas categorias penais e nas demandas socioeconômicas. Não se pode

[...] esquecer que é a doxa que delimita o campo dos fenômenos que a episteme irá tratar: a opinião vem indicar o campo dos comportamentos perversos, e o conhecimento, em relação a ele, permanece tributário da opinião, ainda que modifique, ao longo do trajeto, a extensão do campo. Por isso é que, restringindo-se vigilantemente às distinções necessárias, deveremos, ao mesmo tempo, elucidar um certo número de teorias psicopatológicas das perversões e compreender suas relações com as representações sociais que ajudam nossa cultura a se conformar com a existência das perversões e com a presença dos perversos. (LANTÉRI-LAURA, 1994, p. 14).

Ancorada na positividade científica, a scientia sexualis se referia à perversão como expressão de aberrações congênitas, extravagâncias excepcionais, anulações patológicas e exasperações mórbidas. No centro discursivo da medicina do sexo, colaram-se às perversões termos de patologias biológicas, hereditárias e orgânicas. Instaurou-se um discurso menos preocupado em se interrogar acerca da pretensa gênese biológica da perversão e mais propenso a erradicar os danos provenientes desse imaginário flagelo. A perversão emergira como traço “individual” de degenerescência. Este estaria conectado, diretamente, à má formação do aparelho urogenital (ROUDINESCO, 2008).

O sexo fora colocado no centro do discurso para, por meio dele, manifestar-se o inaudível sujeito (FOUCAULT, 1988). "Personalidade pouco estruturada", "má apreciação do real”, "profundo desequilíbrio afetivo", "sérios distúrbios emocionais": do delito à maneira de ser, intentara-se provar, alicerçando-se na irrefutabilidade da verdade científica, como do ato à conduta, a tendência à perversão subjaz no âmago dos sujeitos (FOUCAULT, 2001). Com efeito, por meio da escruta, mensuração, classificação e correção, pretendia-se prevenir desvios. Impedir o triunfo da animalidade sobre a civilização porque "[...] em seu foro íntimo, o animal humano podia então transformar-se, a qualquer momento, numa besta humana" (ROUDINESCO, 2008, p. 84). Para além do determinismo biológico, a scientia sexualis versava sobre uma ontologia perversa.

O "perverso" aparecera como incapaz de se integrar ao mundo. Alguém com pendores para a desordem, "[...] que comete atos extravagantes, ou extraordinários, que odeia a moral, que renega as leis e pode 
chegar ao crime" (FOUCAULT, 2001, p. 22). 0 ódio à moral advêm de distúrbios genéticos. 0 gosto pela desordem instaura-se no momento mesmo do nascimento, ou antes, na concepção. Os atos extravagantes eram sublimações de forças naturais impossíveis de serem controladas, o crime se desdobrou em consequência última de uma natureza distorcida, encenação final do teatro do grotesco. A scientia sexualis passou a centrar-se não mais nos delitos, ou nas condutas irregulares, mas na origem dessas condutas.

Para auscultar essas condutas, a scientia sexualis lançou mão da confissão, a exagourese. A partir da exagourese se reconstituíam as virtualidades, imagens, obsessões e perigos que poderiam derivar das práticas sexuais. Cinco mecanismos embasam a cientificidade dessa extorsão da confissão sexual. Primeiro: codificação clínica, fazer surgir da confissão um conjunto de sintomas cientificamente inteligíveis, registrando o procedimento confessional no campo dos dados mensuráveis. Segundo: postulado de causalidade geral e difusa entendem-se as práticas sexuais como causa inesgotável e polimorfa, estando o menor desvio, excesso ou defícit, condicionado a variadas consequências. No discurso médico do século XIX, a etiologia sexual estava no cerne de quase todas as doenças e/ou distúrbios. Dos hábitos das crianças "[] às tísicas dos adultos, às apoplexias dos velhos, às doenças nervosas e às degenerescências da raça, a medicina de então teceu toda uma rede de causalidade sexual" (FOUCAULT, 1988, p. 64-65).

$E$ ainda, terceiro: princípio de latência intrínseca, no século XIX a confissão, cientificamente codificada, integrada a um projeto de discurso científico, não elucida tão somente o obscuro do sujeito para o próprio sujeito, mas a própria obscuridade inerente às práticas sexuais. A mecânica da esquiva, clandestinidade da perversão, só revela-se na transmutação da confissão em exames, cirurgias, procedimentos compreendidos unicamente pelos detentores do saber científico. Quarto: método de interpretação duplicatório, complementar do princípio da latência, onde se decifram os dados, formatando-os em regularidades quantitativas, transfigurando-os em possibilidades e riscos. Por fim, medicalização dos efeitos da confissão, inscrição das práticas sexuais no regime normativo patológico, aparecimento da morbidez nas práticas sexuais.

No discurso da medicina positivista, na scientia sexualis, as práticas sexuais consideradas "desviantes", "perversas", emergiram como patologia de caráter orgânico. Derivara dessa classificação técnica a transfiguração da posição dos sujeitos: de agentes ativos a objetos passivos. Recorrendo às minúcias de um entomologista, à precisão de um cirurgião e à neutralidade de um cientista, o discurso médico-positivo, a medicina do sexo, por meio de reeducação, adaptação, não mais de punição, pretendia eliminar taras, conduzir ao padrão ótimo os degenerados, devolver à civilização os "arruinados" pelos traços indeléveis da inerente inferioridade animalesca do ser humano (ROUDINESCO, 2008).

\section{A PSYCHOPATHIA SEXUALISDE KRAFFT-EBING}

Nos postulados de Krafft-Ebing (2001) as práticas sexuais aparecem como desvios e anomalias. Os perversos, nos escritos de Krafft-Ebing, são frutos de uma natureza inversa desviada, malograda, decaída. São o triunfo da animalidade sobre a civilização. Krafft-Ebing conceitua as "perversões" como anomalias funcionais. Tais anomalias funcionais, por sua vez, “[...] são basicamente sinais de uma condição doentia hereditária do sistema nervoso central" que constituem "sinais funcionais de degeneração" (KRAFFT-EBING, 2001, p. 5). Sintetizando as anomalias funcionais em 238 casos clínicos, Krafft-Ebing percorre todas as classes sociais para reafirmar o caráter corruptor das "perversões sexuais".

0 horizonte das personagens de Krafft-Ebing circunscreve uma imensidão diversa, variando de camponeses "idiotas", ou "idiotas" da cidade, exibindo seus órgãos sexuais, penetrando animais, até professores transvestidos, passando por necrófilos da alta sociedade, travestis disfarçados, pais estupradores e aliciadores, religiosos blasfemantes entregues à prostituição etc. 0 denominador comum entre personagens tão distintas é a perversão. Inata e orgânica. 
De acordo com Krafft-Ebing, as anomalias fisiológicas, os desvios orgânicos, são o locus primordial para a investigação das estruturas dos sujeitos. 0 autor cerceia sadismo, masoquismo, fetichismo, e sexualidade antipática, na categoria das neuroses cerebrais. Essas anomalias cerebrais, conduzem frequentemente aos atos criminosos e perversos (KRAFFT-EBING, 2001).

Para Krafft-Ebing (2001), o conjunto das anomalias cerebrais é formado por (1) parestesia, (2) paradoxia, (3) anestesia e (4) hiperestesia. Na parestesia, enquadram-se as "perversões do instinto sexual", definidas como "[...] excitabilidade das funções sexuais por estímulos inadequados" (KRAFFT-EBING, 2001, p. 7). Classificam-se sadismo, masoquismo, fetichismo, e a sexualidade apática, como subdivisões da parestesia. A paradoxia é definida como excitação sexual decorrente de fontes extrínsecas aos processos fisiológicos. A anestesia, ausência de instinto sexual, caracteriza-se pela não excitação sexual decorrente dos impulsos orgânicos advindos dos órgãos sexuais. Na satiríase, desejo acentuado, ou hiperestesia, ao contrário da anestesia, há excesso de excitabilidade sexual em resposta aos estímulos orgânicos, psíquicos ou sensoriais, caracterizando luxúria e lascívia provienentes de libido excessiva.

Krafft-Ebing (2001), conceituando o sadismo, afirma que os atos "sádicos" se relacionam com a impotência do indivíduo "pervertido". Segundo ele, sofrendo de impotência psíquica ou espinhal, o sádico, para equivaler ao coito, entrangula, perfura, flagela, comete atos de violência contra pessoas ou animais. O sadismo, para o autor, caracteriza-se por uma associação de volúpia e crueldade, que, a partir de uma fisiologia malograda, "[...] torna-se fortemente marcada por uma base psiquicamente degenerada" (KRAFFT-EBING, 2001, p. 7). Na descrição de um dos casos, o caso 30, apresentado como exemplar de sadismo, a excitação sexual une-se às "graves taras hereditárias" e à tendência criminosa.

O masoquismo, para Krafft-Ebing, configura-se como o inverso do sadismo. No masoquismo, o êxtase advém da própria sujeição a atos violentos. Para Krafft-Ebing (2001), decorrente do estágio de potência, ou impotência, espinhal ou psíquica, do indivíduo. A violência inflingida a outrem funciona como prévia do coito e em concomitância com o mesmo. Para ele, atos perpetrados por um masoquista, como a procura por castigos corporais, flagelação passiva, humilhações etc., são diretamente proporcionais à intensidade do instinto perverso.

Quanto ao fetichismo, os postulados de Krafft-Ebing (2001) afirmam que seu aspecto patológico relaciona-se à falta de reciprocidade entre o apego a partes do corpo e o sexo. Ausente o objeto investido pela fetichista, torna-se impossível o coito. 0 fetiche "[] varia de um indivíduo a outro, e, sem dúvida, é ocasionado por algum incidente que determina a relação entre uma impressão única e a sensação voluptuosa" (KRAFFT-EBING, 2001, p. 8).

Os homossexuais, observa Krafft-Ebing (2001), por não corresponderem às características sexuais físicas primárias e secundárias, sofrem de uma anomalia puramente psíquica. Esta é definida como sexualidade antipática e se baseia na ausência de "sentimento sexual" pelo sexo oposto. Com efeito, “[...] do ponto de vista clínico e antropológico, essa manifestação anormal apresenta vários graus de desenvolvimento" (KRAFFT-EBING, 2001, p. 9). 0 autor postula que os homossexuais apresentam características psíquicas incipientes. Estas derivam de uma "sexualidade anormal (efeminação-viraginidade)", podendo apresentar "hermafroditismo heterossexual, no âmbito psíquico”.

Com essa definição organicista, a sintomatologia da perversão progride para uma maior especificidade. Quando Krafft-Ebing substantiva Masoch, Sade e as práticas sexuais consideradas "perversas", com tópica definida, encerrando suas características em “disfunções biológicas”, erigindo a partir disso entidades clínicas de caráter orgânico, abstrai, em benefício do discurso organicista positivista, toda uma "[...] concepção do homem, da cultura e da natureza, toda uma nova linguagem" (DELEUZE, 2009, p. 18). 


\section{NOTAS ACERCA DA CRÍTICA DE DELEUZE A KRAFFT-EBING}

Na literatura da scientia sexualis do século XIX, a unidade imposta ao sadismo e ao masoquismo, parece inerente às produções de Sade e Masoch. A respeito desse inatismo unitário entre Sade e Masoch, principalmente nos postulados de Krafft-Ebing, Deleuze afirma que

\begin{abstract}
[...] há uma espécie de masoquismo nos personagens de Sade: em Os 120 de Sodoma, são descritos suplícios e humilhações que os libertinos infligem a si próprios. 0 sádico gosta tanto de ser chicoteado quanto de chicotear; Saint-Fond, em Juliette, é atacado e flagelado por homens que ele próprio encarregara disso, e Borghèse vocifera: 'Eu bem queria que meus caminhos me levassem, como se fosse a última das criaturas, ao destino que merece o abandono; inclusive o cadafalso seria para mim o trono das volúpias". De maneira inversa, há uma espécie de sadismo no masoquismo: no final das suas provações, Séverin, o herói de A Vênus das Peles, se diz curado; ele chicoteia e tortura as mulheres, e se quer "martelo" em vez de "bigorna” (DELEUZE, 2009, p. 39).
\end{abstract}

Essa "pretensa" unidade apriorística, é produto, transformação experienciada. Subordinada à experiência, não podem se afirmar furtando-se às possibilidades. Em determinadas configurações, o "masoquismo" dos heróis sadianos, sádicos para a scientia sexualis, é limítrofe, sanção, "aparece” pós-exercícios "sádicos". O "sadismo" das personagens de Masoch "aparece” pós-expiação, satisfeita a urgência da expiação. Porém, não obstante, as personagens sadianas, arquétipos da fisiologia positivista do sadomasoquismo, nunca aceitariam ser vítima masoquista, e as personagens de Masoch, violentamente substantivadas sob a égide do masoquismo localizado nos "desvios” orgânicos, jamais se submeteriam a um sádico.

As personagens de Masoch intentam educar, persuadir seu “carrasco". É impossível negar a propensão de algumas personagens de Masoch a infringir dor a outrem,

[...] sem dúvida há personagens sádicos que têm um papel no conjunto da situação masoquista. []
Mas esse papel nunca é direto e só pode ser compreendido numa situação conjuntural preexistente. A mulher-carrasco desconfia do personagem sádico que the propõe ajuda, como se pressentisse a incompatibilidade das duas atividades. (DELEUZE, 2009, p. 42).

Logo, afirmando antecipadamente a unidade sadomasoquista, os postulados da medicina do sexo do século XIX, em especial, como fora assinalado, Krafft-Ebing, erraram ao tomar um resultado, provável entre outros, por sintomatologia positiva. Nesse sentido

[...] não se deve, de modo precipitado, achar que se deu cabo dos problemas de sintomas. Às vezes temos de voltar à estaca zero, para dissociar uma síndrome que confundia e arbitrariamente unia sintomas bem diversos. (DELEUZE, 2009, p. 41).

Não propondo serem o sadismo, ou o masoquismo, em consonância com Krafft-Ebing e outros, “síndromes" biologizadas, Deleuze (2009)questiona, a partir de imersão no vocabulário médico, a intransigência deste discurso, recorrendo ao seu núcleo positivo para apresentar as incongruências nas certezas.

o "carrasco" do masoquista, diferentemente do sustentando por Krafft-Ebing, não é, ou finge ser, "sádico" (DELEUZE, 2009). Com base na compreensão da "perversão" como uma possibilidade estilizante de existência, o autor afirma: "[...] cada sujeito de determinada perversão precisa do 'elemento' da mesma perversão, e não de um sujeito de outra perversão" (DELEUZE, 2009, p. 43). Longe do determinismo positivista, encerra-se nessa afirmação a relação subjetiva. No masoquismo, o carrasco e o masoquista, enveredam num processo "masoquizante", distinto do processo sadiano.

Krafft-Ebing substantiva Masoch e engendra um conceito de masoquismo. Com isso, ele une esse conceito, positivamente, com tópica definida, encerrando-o em “disfunções biológicas”, caracterizando-o como desvio, erigindo entidade clínica de caráter orgânico. 


\section{CONSIDERACÕOS FINAIS}

Neste artigo foram apresentados apontamentos acerca do conceito de perversão na scientia sexualis do século XIX e nos postulados de Krafft-Ebing. Elucidara-se como, a partir do século XIX, com a intensificação do pensamento científico-positivo, imputa-se primazia ao discurso médico sobre as práticas sexuais. Posteriormente, fora apresentada uma breve configuração da lógica discursiva dos postulados médicos. Como exemplo primaz dessa lógica, fora analisada a psychopathia sexualis Krafft-Ebing.

A lógica positiva não se limitara às práticas sexuais, tampouco ao contexto europeu. A mesma enraizara-se e permanece fundamentando uma gama abrangente de discursos. Instaurando práticas descontextualizadas, biologizantes, caracterizadas, muitas vezes, por violência física e discursiva, os postulados médicos do século XIX, imersos no positivismo, recorrendo à verdade outorgada à cientificidade escalonante, mensuradora, orientada pelos rígidos padrões matemáticos e anatomofisiológicos, definiram uma raça maldita, os perversos. Incuráveis, senão pelas práticas médicas. Incorrigíveis, senão pela punição, diluída em tecnologias de "reorientação". Os perversos, desviados, malogrados, decaídos, personificação do triunfo da animalidade sobre a civilização, criaturas doentes, permearam o imaginário popular do século XIX, exemplificados por mórbidas gravuras estereotipadas pela literatura médica.

\section{REFERÊNCIAS}

CANGUILHEM, Georges. 0 normal e o patológico. Tradução Maria Thereza Redig de Carvalho Barrocas. Rio de Janeiro: Forense Universitária, 2000.

DELEUZE, Gilles. Sacher-Masoch: o frio e o cruel. Traduçao Jorge Bastos. Rio de Janeiro: Jorge Zahar, 2009.

FOUCAULT, Michel. Microfísica do poder. Tradução

Roberto Machado. Rio de Janeiro: Graal, 1979.

FOUCAULT, Michel. História da sexualidade, 1: a vontade de saber. Tradução Maria Thereza Redig de Carvalho Barrocas. Rio de Janeiro: Graal, 1988.

FOUCAULT, Michel. Os anormais: curso no Collège de France (1974-1975). Tradução Eduardo Brandão. São Paulo: Martins Fontes, 2001.

FOUCAULT, Michel. A verdade e as formas jurídicas. Tradução Roberto Cabral de Melo Machado e Eduardo Jardim Morais. Rio de Janeiro: Nau Editora, 2002.

\section{FOUCAULT, Michel. Segurança, território,} população: curso dado no Collège de France (19771978). Tradução Eduardo Brandão. São Paulo: Martins Fontes, 2008.

GÉLIS, Jacques. O corpo, a Igreja e o Sagrado. In: CORBIN, Alain; COURTINE, Jean-Jacques; VIGARELLO, Georges (Org.). História do corpo: da renascença às luzes. Rio de Janeiro: Vozes, 2009. p.19-130.

GIAMI, Alain. A medicalização da sexualidade. Foucault e Lantéri-Laura: história da medicina ou história da sexualidade? Physis, Rio de Janeiro, v.15, n.2, p.259-284, 2005.

GRIECO, Sara. Corpo e sexualidade na Europa do Antigo Regime. In: CORBIN, Alain.; COURTINE, Jean-Jacques.; VIGARELLO, Georges. (Org.).

História do Ccorpo: da Renascença às Luzes. Rio de Janeiro: Vozes, 2009. p.217-301.

KRAFFT-EBING, Richard von. Psychopathia sexualis: as histórias de caso. Tradução Claudia Berliner. São Paulo: Martins Fontes, 2001.

LANTÉRI-LAURA, Georges. Leitura das perversões: história de sua apropriação médica. Rio de Janeiro: Jorge Zahar, 1994.

\section{ROUDINESCO, Élisabeth. A parte obscura de nós}

mesmos: uma história dos perversos. Tradução Andre Telles Rio de Janeiro: Jorge Zahar, 2008. 
Recebido em: 23 de abril de 2017

Avaliado em: 28 de abril de 2017

Aceito em : 28 de abril de 2017
1 Mestrando em Psicologia pela Universidade Estadual Paulista - UNESP - Faculdade de Ciências e Letras de Assis; Graduado em Psicologia pela Universidade Estadual Paulista - UNESP - Faculdade de Ciências e Letras. E-mail: lucaspeto@gmail.com 
